\section{Individual and Social Factors Related to Urban African American Adolescents' School Performance}

\author{
Cheryl L. Somers \\ Wayne State University \\ Delila Owens \\ Wayne State University \\ Monte Piliawsky \\ Wayne State University
}

The purpose of this study was to examine factors related to the academic success of urban, African American youth. Participants were 118 African American male and female ninth graders from a large urban high school in the Midwest. A majority of students at the school receive free or reduced lunch. Factors studied were social support from five sources (parent, peer, teacher, classmate, close friend) and six educational attitudes and behaviors (educational intentions, educational behavior, personal control, persistence, and understanding of the personal and financial value of educational attainment). The major purpose of this study was to examine the role of these various sources of social support in the educational attitudes and behaviors and academic achievement of this sample of African American youth. Results indicated that social support was mildly correlated with better grades, with parent and peer support relatively the more important forms of support. Moderate and strong correlations were found between the five support variables and most of the educational attitudes and behaviors variables, with support from parents, teachers, and peers most strongly related. The combination of all predictors explained a large proportion of variance in achievement, with educational intentions and personal persistence the strongest contributors. Detailed results and implications of the results are discussed.

\section{Introduction}

It was projected that by the year 2003, students of color would comprise approximately $40 \%$ of the total school population of the United States (U.S. Department of Education, 2003). They would represent over $70 \%$ of the population in large cities in states such as California, Michigan, New York, and Texas (U.S. Department of Education, 2003). Given the above statistic, it is important that educators understand how to support the academic development of students of color.

There is a growing body of literature that documents the achievement gap (Thernstrom \& Thernstrom, 2003; Ferguson, 2002). Unfortunately, African Americans are habitual- 
ly the students who fall short of meeting the educational standards in America (Ford \& Moore, 2004; National Governors Association, 2003; Ogbu, 2003). Although the numbers are more striking in urban school districts (Cooper \& Jordan, 2003; Council of Great City Schools, 1999), there is empirical evidence that, when compared to their White counterparts, African American students are not performing as well as other children in America's schools (Barnett, 2004; Ferguson, 2002; Ogbu, 2003). Thus, African American youth are the focus of this study.

It is imperative that educators continue to address the unique issues faced by urban African American children. Many urban children are from low income families, which are not only economically poor, but also socially underserved. There are a variety of reasons why African American youth do not perform well in school and/or eventually drop out. Dropping out of high school is a symptom of the larger issues affecting youth.

Youth living in urban areas are often faced with violence, poverty, and racism to name a few of the issues. These factors can hinder them both academically and emotionally (Baur, Sapp, \& Johnson, 2000). A link between poverty and school drop out has been identified (Guo, Brooks-Gunn, \& Harris, 1996). Because of their impoverished environments and surroundings, some African American children fail to draw the correlation between academic success and later adult career success. In addition, African American children are keenly aware of the stereotypes associated with their race. This awareness can have an effect on the self-concepts of African American children, thus having an effect on their school performance (Cokley, 2003).

To understand the achievement gap, in an effort to begin to close it, a closer look at the historical background of African American children is crucial. Improving the educational and employment opportunities of urban youth is vital. Thus, it is important to understand factors that contribute to or hinder their academic success. Gallagher (1998), as cited in Socio-Economic Conditions and Student Achievement, high- lighted outside factors that will contribute to student's academic success. He contended that:

"We need to face the unpleasant reality that education, by itself, is a weak treatment. It is clear that there are other variables within the family, within the culture, and within the physical environment, plus limitations within the genetic makeup of the individual, which will have a greater influence on student achievement than our 'improved educational program' for that student."

The role of individual perceptions and social support in educating these youth must be considered. Furthermore, the environment that is related to the schooling process is often not examined. School culture communicates to students how the school views them and their ethnic group (Banks \& Banks, 2001). When the school culture promotes value, respect, and collegiality, students are often more positive. Healthy school climates have an identified impact on the success of students (Karpicke \& Murphy, 1996). African American students sometimes abandon the educational process all together because they are not supported by the school system. Clearly, school culture can have an effect on students' academic achievement (Moore, 2006).

There are additional factors that contribute to an adolescent's academic achievement besides traditional curriculum (e.g., mathematics, english, science). School mobility and school environment have been found to be additional factors that are related to student achievement (Swanson \& Schneider, 1999). It is important to understand how other variables will affect achievement for African American adolescents, especially for those students who are struggling academically. Thus, it is beneficial to explore factors that contribute to adolescents' perceptions, attitudes, and behaviors toward their academic performance.

\section{The Role of Peers}

Research has indicated that peer influence plays a momentous role in adolescents' dispositions toward school (Berndt \& Keefe, 1995; Ogbu, 2003; Wentzel, 1994). Academic support from peers is positively related to the pursuit of 
academic pro-social goals (Wentzel, 1994). However, African American students in particular may receive negative sanctions from their peer group for succeeding academically (Ford \& Moore, 2006). African American students who excel academically could be ridiculed by their peers as "acting white" (Fordham \& Ogbu, 1986; Grantham \& Ford, 2003). Although some adolescents may want to succeed academically, lack of approval from their peers could serve as a barrier. In spite of the ridicule, some African American students succeed academically because they have developed a positive racial identity that serves as a coping strategy to fight off negative performance expectations (Constantine \& Blackmon, 2002).

\section{The Role of Parents}

Additionally, parental support plays a role in the academic success of students. Karavasilis, Doyle, and Margolese (1999), wrote that encouraging and supportive relationships with parents fostered a greater sense of autonomy in adolescence. Students in these types of families are able to comfortably explore their environments and return to the family for emotional support. Research has also shown that parental involvement is particularly crucial for minority children (Epstein, 2001; Henderson \& Mapp, 2002; $\mathrm{Xu}, 2002)$. Trusty (1998) found that parental involvement and parental attempts to integrate into their child's schooling was predictive of student academic achievement. Thus, teachers and administrators may promote the academic success of African American students by exploring avenues to get parents involved in their schooling. Additionally, broader social support, discussed next, has been linked to academic success for students.

\section{The Role of Social Support}

Social support for adolescent school retention is also important (Guest \& Biasini, 2001). Four important factors have been identified as influencing the academic success of African American adolescents. School, parents, peers, and neighborhood environment all play roles in African American students' academic success (Newman, Myers, Newman, Lohman, \& Smith, 2000). Some students may be expected to succeed academically, while others may not. These expectations can vary by context.
Other social variables may also account for the academic success of African American students as well as their task engagement in the classroom. Broader conceptions of social factors that may influence direct task engagement in classroom activities have been offered. For example, Owens, Hamm, Jaynes, and Rawls (2007) found that urban low-income African American youth reported extracurricular activities such as babysitting, childrearing, and after-school employment as social influences that were related to their task engagement in classroom assignments. All activities reportedly had both positive and negative associations with youth outcomes. However, all students indicated that despite their environmental influences, obtaining an education was extremely important (Owens, et al., 2007).

\section{Ecological Theory and The Transition to High School}

Much research has examined academic achievement among urban African American students in grades K-12 in the last two decades. This research has focused on the issues African American students face in pursuit of academic success (e.g., Flowers, Milner, \& Moore, 2003; Howard, 2003; Ogbu, 2004). Results have shown that there are a variety of factors that influence academic success among urban African American students. Many studies only examined a few variables at a time. The ecological perspective advanced by Bronfenbrenner (1979) is likely to explain a larger portion of variance in academic success because it considers multiple levels of contexts in a child's life. For example, the roles of family, self, and peers are considered in the ecological model, as well as the roles of outside influences such as parents' jobs, societal values and dynamics, etc.

Also, little empirical data exists regarding the transition from middle school to ninth grade. However, existing literature indicates that for freshmen, the transition to high school can be anxiety-producing. For some ninth graders, the transition to high school brings negative consequences such as low grades and poor school attendance (Barone, Aguirre-Deandreis, \& Trickett, 1991). Researchers such as Eccles, Midgley, Wigfield, \& Buchanan (1993) have demonstrated that school transitions are related 
to decreased academic performance, lower self esteem, less involvement in activities, and greater feelings of anonymity. Coupled with the challenges of the period of adolescence in general, school performance can substantially suffer. For this reason, we focus specifically on ninth grade students in the current study.

\section{Purpose of The Study}

Based on the aforementioned literature review, the purpose of this study was to examine how factors from several life contexts were related to the school success of urban, African American youth. The end goal was to broaden our understanding of how we may intervene to more effectively assist them. The specific study variables were social support from five sources (parent, peer, teacher, classmate, close friend), six educational attitudes and behaviors (educational intentions, educational behavior, personal control, persistence, and understanding of the personal and financial value of educational attainment), and academic achievement in the fall of 9th grade. The primary research questions were: 1) what is the role of social support in the educational attitudes and behaviors of these youth?; and, 2) what are the combined and comparative roles of both social support and educational attitudes and behaviors in predicting academic achievement for this sample of African American youth?

\section{Method}

\section{Participants}

The participants in this study were 118 African American students (43 males, 75 females) in the ninth grade of a large, urban, public school in the Midwest. The school has a $65 \%$ free and reduced lunch rate, and thus, a majority of students are likely to be economically disadvantaged. This data was not collected on individual study participants. The school student racial/ethnic demographic is $96 \%$ African American. The community surrounding the school is best characterized as working-class homeowners. The city is also one of the nation's poorest cities with one in three children living below the federal poverty level (Kantor, 2000). The students participating in the study came from several sections of general education science classes, which all 9th graders have to take.
No parents refused their children's participation, and most all students were administered the survey. Thus, it is expected that this sample well represents the school's 9th grade population.

\section{Measures}

\section{Social support}

The following five measures were taken from the Children and Adolescent Social Support Scale (CASSS) (Malecki, Demaray, \& Elliott, 2000). Participants responded to items using a six-point scale, ranging from $1=$ "never," to $6=$ "always." Malecki et al. (2000) reported Cronbach's alphas of .89 to .95 in previous research. Below, Cronbach's alphas for the current sample are reported. The items on these five measures utilized 6-point subscales and answered ("never" to "always"). The measures are as follows:

(1) Parent support (9 items, a=.90, e.g., "My parents show they are proud of me");

(2) Teacher Support (12 items, a=.92, e.g., "My teacher takes time to help me learn something well”);

(3) Classmate support (8 items, a =.92 e.g. "My classmates give me ideas when I don't know what to do");

(4) Close friend support (items, a =.96; "My close friends give me ideas when I don't know what to do");

(5) General school support (12 items, a =.97; "People at school listen to me when I need to talk").

\section{Educational attitudes and behaviors}

The following six measures were used to assess students' educational attitudes and behaviors. Measures six through nine, listed below, were derived from Somers \& Piliawksy (2004), and were found to have adequate reliability. Participants responded to items using a 5-point scale ranging from $1=$ "strongly disagree" to $5=$ "strongly agree”. Cronbach's alphas were computed to the current sample and are reported for each instrument below as appropriate.

(6) Educational Intentions (4 items, $a=72$; e.g., "I plan to finish high school”); 
(7) Educational Commitment Behavior (3 items, a =.60; e.g., " I work hard on my school grades");

(8) Identification of Financial Value of Education (1 item, e.g. "It will be very easy for me to make money without a high school diploma”);

(9) Identification of Personal Value of Education (1 item, e.g." I am motivated to finish high school for my own personal satisfaction”).

The 10th measure was responded to using a 5point scale ("always true" to "never true").

(10) Belief in Personal Control Scale (Berrenberg, 1987) (45 items, a =.67; e.g., "If I just keep trying, I can overcome any obstacle").

The final instrument was responded to using a "yes/no" format.

(11) Persistence Scale for Children (Lufi \& Cohen, 1987) (40 items, a=.70; e.g. "I often do not complete many activities I begin”).

\section{Grades}

School grade point averages were obtained at the first report card marking in the fall of ninth grade. Grades used a 4.0 scale, with 4.0 being the highest possible GPA.

\section{Procedure}

Participants were recruited from several classrooms within the school on a voluntary basis. Any child or parent who was interested was permitted involvement. The potential benefit expressed to parents was that they would have the opportunity to attend a free lecture about the study results, including a summary of the research on which factors best predicted these students' academic success. Instruments were administered in classrooms under the supervision of the teachers and researchers. Although students were informed of their freedom to leave any items blank, response rates were nearly $100 \%$.

\section{Results}

The purpose of this study was to better understand which factors are related to the school success of urban, African American youth, so to broaden how professionals could more effec-

\begin{tabular}{|l|c|c|c|c|}
\hline \multicolumn{1}{|c|}{ Variable } & Mean & SD & Min. & Max. \\
\hline Parent support & 4.52 & 1.15 & 1.00 & 6.00 \\
\hline Teacher support & 4.17 & 1.34 & 1.00 & 6.00 \\
\hline Classmate support & 3.71 & 1.22 & 1.00 & 6.00 \\
\hline Close friend support & 4.70 & 1.24 & 1.00 & 6.00 \\
\hline School support & 3.41 & 1.57 & 1.00 & 6.00 \\
\hline Educational intentions & 4.65 & 0.56 & 2.00 & 5.00 \\
\hline Educational commitment behavior & 4.11 & 0.56 & 2.00 & 5.00 \\
\hline Identification of financial value of education & 3.52 & 0.56 & 2.00 & 5.00 \\
\hline Identification of personal value of education & 4.70 & 0.52 & 2.00 & 4.00 \\
\hline Belief in personal control & 3.11 & 0.33 & 2.00 & 4.00 \\
\hline Persistence & 1.57 & 0.11 & 1.35 & 1.88 \\
\hline GPA - beginning of 9th grade & 1.89 & 0.77 & 0.40 & 3.67 \\
\hline Note. B=Standardized beta coefficient. ${ }^{*}=$ p<.05. & & & & \\
\hline Table 1. Descriptive Statistics for all Variables & & & \\
\hline
\end{tabular}


tively assist them. Table 1 includes descriptive information about all variables included in the study.

First, a multiple linear regression analysis was run with the five support variables entered as the predictor variables (parents, classmates, teachers, close friends, and school) and GPA as the criterion. These support variables at the beginning of 9th grade were not significantly predictive of their GPAs that fall. However, the Pearson correlation coefficients indicated that there were mild statistically significant relations between each of the social support variables and fall GPA (range of $r=.18-.26, p<.05$; See Table 2).

Next, correlations were run between the five support variables and the six education-related attitudes and behaviors. Moderate and strong correlations were found between the five support variables and most of the educational attitudes and behaviors variables (range of $\mathrm{r}=.22$ $.56, \mathrm{p}<.01)$. See Table 2.

Support from parents, teachers, and peers were consistently correlated with these attitudes and behaviors. Specifically, they were correlated with educational intentions to complete school and pursue further schooling, educational commitment behavior, and identification of the personal value of an education. Only parent support was related to identification of the financial value of an education.

However, support from best friends and schools were only minimally correlated with educational attitudes and behaviors. Additionally, correlations were run between social support and belief in personal control, as well as persistence. Only parent support was related to greater persistence levels and belief in personal control for the adolescents in this study.

Finally, using hierarchical linear regression analyses to predict GPA in the fall of ninth grade, the five support variables were entered on step one and the six attitudinal and behavioral variables were entered on step two (educational intentions, educational commitment behavior, personal value of education, financial value of education, persistence, and belief in personal control). This was done in order to examine the individual and combined contributions of the 11 predictor variables selected for

\begin{tabular}{|c|c|c|c|c|c|}
\hline \multicolumn{6}{|c|}{ Source of Social Support } \\
\hline Behavior/Attitude & Parents & Teachers & Classmates & Close Friends & School \\
\hline Educational intentions & $.454 * * *$ & $.386^{* * *}$ & .367 & .118 & $.218^{*}$ \\
\hline $\begin{array}{l}\text { Educational commitment } \\
\text { behavior }\end{array}$ & $.446^{* * *}$ & $.456^{* * *}$ & $.296^{* *}$ & .173 & $.314^{* *}$ \\
\hline $\begin{array}{l}\text { Identification of financial } \\
\text { value of education }\end{array}$ & $.225^{*}$ & .022 & .035 & -.078 & .088 \\
\hline $\begin{array}{l}\text { Identification of personal } \\
\text { value of education }\end{array}$ & $.557 * * *$ & $.355^{* * *}$ & $.313^{* *}$ & -.011 & .194 \\
\hline Belief in personal control & $.301 *$ & .231 & .223 & .237 & -.076 \\
\hline Persistence & $.347^{* *}$ & .221 & .191 & .147 & .141 \\
\hline \multicolumn{6}{|l|}{ Achievement } \\
\hline GPA - start of 9th grade & $.258^{*}$ & $.202^{*}$ & $.238^{*}$ & $.229 *$ & .173 \\
\hline \multicolumn{6}{|c|}{ Note. ${ }^{* * *}=\mathrm{p}<.001,{ }^{* *}=\mathrm{p}<.01,{ }^{*}=\mathrm{p}<.05$} \\
\hline \multicolumn{6}{|c|}{$\begin{array}{l}\text { Table 2. Correlations Between Social Support and GPA and Educational Behaviors and } \\
\text { Attitudes }\end{array}$} \\
\hline
\end{tabular}


this study. GPA in the fall of ninth grade was entered as the criterion variable. Results revealed that this combination of predictors provided a statistically significant explanation of variance in fall GPA $\left(\mathrm{R}^{2}=.569, \mathrm{p}<.05\right)$. Beta weights revealed that only educational intentions to finish high school and personal persistence significantly contributed to the equation above and beyond the others (respectively b $=.688$ and .391). See Table 3.

\section{Discussion}

The main goal of this study was to explore the role of factors from several life contexts in the school success of African American ninth grade youth who live in an urban setting. The unique contribution of this study is that it considers a host of ecological factors that are related to school success. The data indicate that this group of adolescents varied widely in their aca- demic success in the transition to 9th grade, with many of them receiving below average grades. Thus, it appeared especially important to better understand what factors predict higher achievement.

Overall, certain variables appear to be more related to adolescents' achievement than others. The five types of social support alone were not predictors of grades, but they were correlated with grades. Parents and peers were most strongly correlated, teachers next, and peers and schools least strongly correlated. Interestingly, social support was correlated with educational intentions, educational behavior, and identification of the personal and financial value of education, some of which were predictive of grade point average. Personal control, but not persistence, was correlated with positive outcomes as well.

\begin{tabular}{|c|c|c|c|c|}
\hline Predictor Variables & Multiple $\mathbf{R}^{2}$ & Sig. of $\mathbf{R}^{2}$ & B-weight & Sig. of B \\
\hline Step 1 & .318 & $.034^{*}$ & & \\
\hline Parent support & & & .314 & .131 \\
\hline Teacher support & & & .259 & .294 \\
\hline Classmate support & & & -.117 & 635 \\
\hline Close friend support & & & .322 & .092 \\
\hline School support & & & -.012 & .959 \\
\hline Step 2 & .569 & $.015^{*}$ & & \\
\hline Educational intentions & & & .688 & $.033^{*}$ \\
\hline $\begin{array}{l}\text { Educational commitment } \\
\text { behavior }\end{array}$ & & & -.185 & .232 \\
\hline $\begin{array}{l}\text { Identification of financial } \\
\text { value of education }\end{array}$ & & & -.514 & .142 \\
\hline $\begin{array}{l}\text { Identification of personal } \\
\text { value of education }\end{array}$ & & & -.089 & .622 \\
\hline Belief in personal control & & & .081 & .596 \\
\hline Persistence & & & .391 & $.032 *$ \\
\hline
\end{tabular}

Note. $\mathrm{B}=$ Standardized beta coefficient. ${ }^{*}=\mathrm{p}<.05$.

Table 3. Regression Analysis predicting Beginning 9th Grade GPA. 
Social support, from each of the sources studied here, is clearly an important factor in school success, both in terms of GPA and positive educational attitudes and behaviors. Social support and academic success has been routinely studied in the literature. It is important to consider the role of social support, why it is important, what it means, and what we could/should be doing in schools and with parents. Research has shown that the most consistent predictor of academic achievement and students' attitudes toward learning is parental expectations (Reynolds et al., 1993). The data here suggest that social support is important in a child's academic success. Schools should be looking at creative ways to facilitate discussions between parents and teachers.

The source of social support found to be most related to academic success is important to consider. The correlation between support from parents and peers and grade point average supports previous literature. African American parents generally want their children to excel academically. Education is seen as a valued commodity in the African American community. Therefore, many African American parents actively encourage their children to excel academically and do well in school (BoydFranklin, 1989; Coleman, 1986; Hill, 1972). Hara (1998) wrote that continual parental involvement will increase academic achievement among high school students. Jeynes (2000) found that parental involvement does affect academic achievement in students from minority groups. However, he also wrote that there is a greater need to understand the varied aspects of parental involvement in students' education, and thus, socio-economic status should also be considered.

There is a tendency for lower socio-economic status families to be unaware of their rights and roles in the school for a number of reasons. Oftentimes, lower income parents are reluctant to get involved in their child's education because they may not see themselves as part of their children's educational process. Parents may not feel adequate enough to contribute to school success, and school environments may not be welcoming to some parents (HooverDempsey \& Sandler, 1997). Much more educa- tion needs to occur in order to help these parents realize their potential power to help children succeed. Perhaps legislation is needed to ensure that school districts develop policies to engage all families. One example of such legislation is Senate Bill 307, passed in Michigan in 2004, which mandated that schools develop parental involvement policies and procedures.

Similarly, our finding that peer support was related to grade point average is consistent with the literature. Adolescents typically spend more time with their peer group than their parents. They are oftentimes with their peer group without supervision (Brown, 1990). Historically, research has found that peer influence is more prevalent in early adolescence versus late adolescence (Berndt, 1979; Collins and Thomas, 1972). Researchers have found that on the whole, African American students may not receive academic support from their peers (Steinberg, Dornbusch, \& Brown, 1992). Fordham and Ogbu (1986) wrote that African American students who excel academically may be perceived by their peers as "acting white". These findings suggest that some African American students may not perform to their fullest potential for fear of losing the acceptance of their peer group. The school should be involved in efforts to break down such stereotypes about who can allow themselves to be successful.

In addition to social support, other factors must be considered in understanding academic success. Although many of the relations found in these analyses reflect small to moderate strength correlations, educational intentions or aspirations to complete high school was the variable that emerged as significant above and beyond the rest for this sample of adolescents. Although there was a small degree of inter-correlation (multi-collinearity) among the independent variables that were simultaneously entered into the regression analysis, this variable nonetheless contributed significant explanation of variance in GPA. Those students with intentions to complete high school are likely motivated to achieve by future possibilities. It is also likely that social support has helped them to feel motivated to aspire for high school completion and beyond. It seems important to help 
all adolescents, especially those at risk of dropping out, to see the relevance of what they are learning, and to realize the long term effects of their educational behavior today.

This help could be achieved through interventions designed to help adolescents feel more personal control and power over their long-term plans and outcomes. Interestingly, belief in personal control was significantly related to outcomes, along with social support. This may at least partially explain why educational intentions to finish high school were so important in explaining variance in GPA.

Also, it was notable that in this study none of the social support variables were related to personal persistence. It may be that personal persistence is an enduring personality trait that is not necessarily linked to lack of success. Although persistence clearly has benefits for success, it may not necessarily be cause for drastic concern when a child fails to be as persistent as we might prefer. Instead, these children may simply require more extrinsic motivators to ensure that they follow a successful path, at least until they develop more intrinsic habits.

Given our findings, it is important that young adolescents are involved with long term programs that offer social support. Both prevention and intervention efforts are important, considering all contexts of adolescents' lives. Multimodal interventions are important, tapping family, community, school, and individual levels. We can start at the individual child and adolescent level, but each child's entire support network also needs to scaffold their educational goals, plans, and daily progress toward meeting goals.

Overall, results of this study revealed that for this sample of urban, African American children, social support from classmates, parents, teachers, close friends, and schools all were significantly correlated with their 9th grade GPAs and educational intentions. Given the findings, there are several implications for educators. Even though the correlations between school and teacher support and GPA were small, they were still significant and necessitate the role of educators in the interventions needed. Clearly, teacher relationships with students can have a positive association with academic success. The implications for educators also include the need for further examination of broader research that examines parental relationships with schools and why parents become involved. In addition, schools and community organizations must develop strategies and policies to broaden parental involvement in schools. A theoretical model that examines the parental involvement process in schooling practices and a definition of what it means for parents to be involved is imperative.

There are several limitations that could be improved for future research, including sample size and more precise or inclusive measurements of achievement than GPA alone. Crosscultural research would also provide information about whether or not these dynamics are unique to African American, urban populations. Nonetheless, these findings both support previous literature and contribute new information about urban, African American adolescents as they make the sometimes turbulent transition to ninth grade. These findings can be used to drive not only future research questions but applied prevention and interventions efforts as discussed above.

\section{References}

Banks, J.A., \& Banks, C.A.M. (2001). Multicultural education/Issues and perspectives. (5th ed.). Boston: Allyn and Bacon.

Baur, S., Sapp, M., \& Johnson, D. (2000). Group Counseling Strategies for Rural At-Risk High School Students. High School Journal, 83. 41-51.

Barnett, W. S. (2004). Better teachers, better preschools: Student achievement linked to teacher qualifications. In Preschool Policy Matters, 2, 1-11. New Brunswick, NJ: National Institute for Early Education Research, Rutgers.

Barone, C., Aguirre-Deandreis, A. I., \& Trickett, E. J. (1991). Mean-ends problem-solving skills, life stress, and social support as mediators of adjustment in the normative transition to high school. American Journal of Community Psychology, 19 (2), 207-225.

Berrenberg, J. L. (1987). The belief in personal control scale: A measure of God-mediated and exaggerated control. Journal of Personality Assessment, 51, 194206.

Berndt, T. (1979). Developmental changes in conformity to peers and parents. Developmental Psychology, 15, 606-616.

Berndt, T., \& Keefe, K. (1995). Friends' influence on adolescents' adjustment to school. Child Development, 66 (5), 1312-1329.

Boyd-Franklin, N. (1989). Black families in therapy: A multi-systems approach. NY: Guildford Press. 
Bronfenbrenner, U. (1979). The ecology of human development. Cambridge, MA: Harvard University Press.

Brown, B. B. (1990). Peer groups and peer cultures (pp. 171-196). In S. S. Feldman and G. R. Elliott (Eds), At the threshold: The developing adolescent. Cambridge, MA: Harvard University Press.

Cokley, K. O. (2004). What do we know about the motivation of African American students? Challenging the 'anti-intellectual' myth": Correction. Harvard Educational Review, 73 (4), 524-558.

Coleman, B.P. (1986). The Black educator: An endangered species. Journal of Negro Education, 55 (3), 326-334.

Collins, J. K., \& Thomas, N. T. (1972). Age and susceptibility to same-sex peer pressure. British Journal of Educational Psychology, 42, 83-85.

Constantine, M. G., \& Blackmon, S. M. (2002). Black adolescents' racial socialization experiences: Their relations to home, school and peer self-esteem. Journal of Black Studies, 32, 322-335.

Cooper, R., \& Jordan, W. J. (2003). Cultural issues in comprehensive school reform. Urban Education, 38, 380-397.

Council of Great City Schools (1999). Closing the achievement gaps in urban schools: A survey of academic progress and promising practices in the great city schools. Washington, DC: Author.

Eccles, J. S., Midgley, C., Wigfield, A., Buchanan, C. M. (1993). Development during adolescence: The impact of stage environment fit on young adolescent's experiences in schools and families. American Psychologist: Special Issue: Adolescence, 48 (2), 90-101.

Epstein, J. (2001). School, family, and community partnerships. Boulder: Westview Press.

Ferguson, R. E. (2002). Addressing racial disparities in high-achieving suburban schools. Retrieved from http://ww.ncrel.org/policy/pubs/html/pivol113/dec20 02b.htm, February 17, 2005.

Flowers, L. A., Milner, H. R., \& Moore III, L. (2003). Effects of locus of control on African American high school seniors' educational aspirations: Implications for preservice and inservice high school teachers and counselors. The High School Journal, 87, 39-50.

Ford, D. Y., \& Moore III, J. L. (2004). The achievement gap and gifted students of color. Understanding Our Gifted, 16, 3-7.

Ford, D. Y., \& Moore III, J. L. (2006). Eliminating deficit orientations: Creating classrooms and curricula for gifted students from diverse cultural backgrounds. In D. W. Sue and M. Constantine (Eds.), Racism as a barrier to cultural competence in mental health and educational settings. Indianapolis, IN: John Wiley and Sons.

Fordham, S., \& Ogbu, J.U. (1986). Black students' school success: Coping with the "burden of acting White." The Urban Review, 18 (3), 176-206.

Gallagher, J. J. (July 8, 1998). Education, alone, is a weak treatment. Education Week, www.edweek.org. In Socio-Economic Conditions and Student Achievement. Retrieved http://www.weac.org/ greatschools/Issuepapers/socioconditions.htm (11/21/04).

Grantham, T. C., \& Ford, D. Y. (2003). Beyond self-concept and self-esteem: Racial Identity and gifted African American students. The High School Journal, 87, 18-29.
Guest, K. C., \& Biasini, F. J. (2001). Middle childhood, poverty, and adjustment: Does social support have an impact? Psychology in the Schools, 38 (6), 549-560.

Guo, G., Brooks-Gunn, J., \& Harris, K. M. (1996). Parents' labor force attachment and grade retention among urban black children. Sociology of Education, 69 (3), 217-236.

Hara, S. R. (1998). Parent involvement: The key to improved student achievement. School Community Journal, 8, 9-19.

Henderson, T. A. \& Mapp, K. L. (2002). A new wave of evidence: The impact of school, family and community connections on student achievement. Metairie, LA: Southwest Educational Development Laboratory, National Center for Family and Community Connections with Schools.

Hill, R. (1972). The strengths of Black families. Washington, DC: National Urban League.

Hoover-Dempsey, K. V., \& Sandler, H. M. (1997). Why do parents become involved in their children's education? Review of Educational Research, 67 (1), 3-42.

Howard, T. C. (2003). "A tug war for our minds": African American high school students' perceptions of their academic identities and college aspirations. The High School Journal, 87, 4-17.

Jeynes, W. (2000). Assessing school choice: A balanced perspective. Cambridge Journal of Education, 30 (2), 223-241

Kantor, P. (2000). Can Regionalism Save Poor Cities? Urban Affairs Review, Vol. 35, No. 6, 794-820.

Karavasilis, K., Doyle, A. B., \& Margolese, S. K. (1999). Links between parenting styles and adolescent attachment. Poster presented at the biennial meetings of the Society for Research in Child Development, Albuquerque, NM.

Lufi, D., \& Cohen, A. (1987). A scale for measuring persistence in children. Journal of Personality Assessment, 51, 178-185.

Malecki, C. K, Demaray, M. K., \& Elliott, S. N. (2000). The child and adolescent social support scale. Dekalb, IL: Northern Illinois University.

Moore III, J. L. (2006). A qualitative investigation of African American males' career trajectory in engineering: Implications for teachers, school counselors, and parents. Teachers College Record, 108, 246-266.

National Governors Association. (2003). Ready for tomorrow: Helping all students achieve secondary and postsecondary success. Washington, DC: Author.

Newman, B., Myers, M. C., Newman, P. R., Lohman, B. J., \& Smith, V. L. (2000). The transition to high school for academically promising, urban, low-income African American youth. Adolescence, 35, 45-66.

Ogbu, J. U. (2003). Black American students in an affluent suburb: A study of academic disengagement. Mahwah, NJ: Lawrence Erlbaum.

Ogbu, J. U. (2004). Collective identity and the burden of "acting white" in Black history, community, and education. The Urban Review, 36, 1-35.

Owens, D., Hamm, D., Jaynes, C., \& Rawls, G. (2004). Factors affecting task engagement in urban African American adolescents. A pilot study. Ohio Journal of Professional Counseling. http://www.ohiocounselingassoc.com 
Reynolds, A. J., Mavrogenes, N. A., Hagemann M., \& Bezruczko, N. (1993). Schools, families, and children: Sixth year results from the longitudinal study of children at risk. Chicago: Chicago Public Schools, Department of Research, Evaluation, and Planning.

Somers, C. L., \& Piliawsky, M. (2004). Drop-out prevention among urban, African American adolescents: Program evaluation and practical implications. Preventing School Failure, 48 (3), 17-20.

Steinberg, L., Dornbusch, S. M., \& Brown, B. B. (1992). Ethnic differences in adolescent achievement: an ecological perspective. American Psychologist, 46(6), 723-729.

Swanson, C. B., \& Schneider, B. (1999). Students on the move: Residential and educational mobility in America's schools. Sociology of Education, 72(1), 54-67

Thernstrom, S. \& Thernstrom, A. (2003). No excuses: Closing the racial gap in learning. New York: Simon and Schuster.

Trusty, J. (1998). Family influences on educational expectations of late adolescence. The Journal of Educational Research, 91, 260-270.

U.S. Department of Education. (2003). Overview of public elementary and secondary schools and districts: School year 2001-02: Statistical analysis report. NCES 2003-411.Retrieved on May 3, 2005 from http://nces.ed.gov/pubs2003/2003411

Wentzel, K.R. (1994). Relations of social goal pursuit to social acceptance, classroom behavior, and perceived social support. Journal of Educational Psychology, 86(2), 173-182.

$\mathrm{Xu}, \mathrm{J}$. (2002). Middle school family involvement in urban settings: Perspectives from minority students and their families. Paper presented at the annual meeting of the American Educational Research Association, Seattle, WA.

\section{घ88}


Copyright of High School Journal is the property of University of North Carolina Press and its content may not be copied or emailed to multiple sites or posted to a listserv without the copyright holder's express written permission. However, users may print, download, or email articles for individual use. 